(2) Open Access Full Text Article

\title{
Pretransplant metabolic syndrome and its
} \section{components predict post-transplantation diabetes mellitus in Chinese patients receiving a first renal transplant}

This article was published in the following Dove Medical Press journal:

Therapeutics and Clinical Risk Management

\author{
Ruiming Cai' \\ Meng Wu² \\ Yanfang Xing ${ }^{3}$ \\ 'Department of Organ \\ Transplantation, The Third Affiliated \\ Hospital of Guangzhou Medical \\ University, Guangzhou 510150 , \\ Guangdong, China; ${ }^{2}$ Department of \\ Nephrology, Longyan First Hospital, \\ Longyan 364000, Fujian, China; \\ ${ }^{3}$ Department of Nephrology, The Third \\ Affiliated Hospital of Guangzhou \\ Medical University, Guangzhou \\ 5I0I50, Guangdong, China
}

Correspondence: Yanfang Xing Department of Nephrology, The Third Affiliated Hospital of Guangzhou Medical University, No 63 Duobao Rd, Liwan District, Guangzhou 510150 , Guangdong, China

Tel +86020 8I 292889

Email25744105।2@qq.com
Background: Post-transplantation diabetes mellitus (PTDM) remains a major clinical challenge following renal transplant. Identification of pretransplant modifiable risk factors may allow timely interventions to prevent PTDM. This study aims to determine whether pretransplant metabolic syndrome and its components are able to predict PTDM in Chinese patients receiving their first renal transplant.

Patients and methods: We conducted a single-center retrospective study of 633 non-diabetic patients receiving a first kidney transplant. PTDM was diagnosed between 1 month and 1 year post-transplant. Multivariable logistic regression and Cox proportional hazards model were applied to detect potential pretransplant risk factors for PTDM.

Results: One year post-transplant, 26.2\% of recipients had developed PTDM. PTDM patients had significantly higher fasting plasma glucose (FPG) $(P=0.026)$ and body mass index $(\mathrm{BMI})$ $(P=0.006)$ than non-PRDM patients, and lower levels of high-density lipoprotein cholesterol $(P=0.015)$. The presence of metabolic syndrome was an independent risk factor for PTDM, as assessed by multivariable logistic regression analysis (OR 1.28, 95\% CI 1.04-1.51, $P=0.038$ ) and Cox proportional hazards model (OR 2.75, 95\% CI 1.45-6.05, $P=0.021)$. Moreover, both FPG $>5.6 \mathrm{mmol} / \mathrm{L}$ and $\mathrm{BMI}>28 \mathrm{~kg} / \mathrm{m}^{2}$ (obesity) were able to predict PTDM.

Conclusion: Our results suggest that the presence of metabolic syndrome and its components, impaired fasting glycemia and obesity, are independent risk factors for PTDM in Chinese nondiabetic patients receiving a first renal transplant. Interventions aimed at improving pretransplant metabolic syndrome may reduce the incidence of PTDM.

Keywords: post-transplantation diabetes mellitus, renal transplant, metabolic syndrome, body mass index, fasting plasma glucose

\section{Introduction}

Post-transplantation diabetes mellitus (PTDM) is a major clinical challenge following kidney transplantation. ${ }^{1,2}$ It has been estimated that around $15 \%-30 \%$ of non-diabetic recipients develop PTDM in the first year after renal transplantation and that, more appalling, nearly half of the recipients develop PTDM within 5 years post-transplant. ${ }^{3-5}$ PTDM is frequently associated with subsequent graft failure and an increased mortality rate, and has also incurred a huge economic burden on recipients. ${ }^{3,4,6}$ Therefore, there are compelling reasons to develop clinical strategies for prevention, although the pathogenesis of PTDM remains largely unknown. 
Because the majority of PTDM develops in the first year after transplantation, pretransplant risk factors are considered to play crucial roles in the development of PTDM. ${ }^{5,7,8}$ The established pretransplant risk factors include older age, ${ }^{3,7,9,10}$ minority race, ${ }^{3,11}$ higher body mass index (BMI), ${ }^{3,7-9}$ family history of diabetes mellitus (DM) ${ }^{7,9,12}$ hepatitis $\mathrm{C}$ virus (HCV) infection, ${ }^{3,10,13}$ elevated pretransplant fasting plasma glucose (FPG), triglycerides (TG) and cholesterols, $3,5,7,7,10$ elevated plasma insulin, ${ }^{8}$ and recipients of deceased donor kidneys. ${ }^{10,12}$ In addition to the pretransplant risk factors, it is widely recognized that the immunosuppressive regimen after kidney transplantation is closely associated with the development of PTDM. ${ }^{7,810,14}$ Importantly, identification of the risk factors may allow timely intervention for the prevention of PTDM. For example, it is suggested that lifestyle modification (eg, restrained calorie intake and moderate to intense physical activity) before transplantation, aiming to reduce BMI, may lower the incidence of PTDM. ${ }^{1}$ Although most of these risk factors are unlikely to be functionally validated, the strategy of identifying modifiable pretransplant risk factors is critical and fundamental for the prevention of PTDM after renal transplantation.

The identified pretransplant risk factors listed in the previous paragraph are primarily components of metabolic syndrome. Bayer et al documented that pretransplant metabolic syndrome is an independent predictor for PTDM and, most importantly, is a potential target for intervention to prevent PTDM. ${ }^{5}$ To our knowledge, however, the impact of metabolic syndrome and its components on PTDM is rarely studied in areas such as China, where the incidence of DM is increasing rapidly. Therefore, this study aims to reveal the impact of metabolic syndrome and its components on the development of PTDM in a cohort of Chinese non-diabetic patients receiving their first kidney transplant.

\section{Patients and methods}

\section{Patient population}

We retrospectively and systemically reviewed the clinical records of 1,308 patients undergoing renal transplantation at the Department of Organ Transplantation, The Third Affiliated Hospital of Guangzhou Medical University, between 2002 and 2016. Clinical information was retrieved and assembled from the local electronic database. The extraction and reporting of the data were approved by the local ethics committee. All patients routinely provided written informed consent immediately before the operation, allowing deposition, extraction, and reporting of their clinical information and data. Exclusion criteria included recipients with: 1) a history of DM or with DM before transplantation; 2) allograft functioning $\leq 1$ year; 3 ) a history of renal transplantation; 4) other solid organ transplants; 5) $\leq 1$-year follow-up post-transplantation; and 6) incomplete data on components of metabolic syndrome (indicated below). Finally, data from 633 non-diabetic recipients receiving a first renal transplant were assembled and analyzed.

\section{Immunosuppression}

All the included recipients were mainly on a tacrolimusbased regimen as their initial immunosuppressant treatment. In general, doses of tacrolimus were titrated to plasma levels of $8-15 \mathrm{ng} / \mathrm{mL}$ during the first 6 months and titrated to $5-7 \mathrm{ng} / \mathrm{mL}$ by the first year. At the time of transplant, recipients also received mycophenolate mofetil (MMF) as well as a 5-day tapering course of glucocorticoids (methylprednisolone intravenous injection $500 \mathrm{mg}, 250 \mathrm{mg}$, and $125 \mathrm{mg}$ on days 1, 2 and 3, respectively; oral $60 \mathrm{mg}$ prednisone on day 4 , and $30 \mathrm{mg}$ on day 5). For those requiring ongoing steroid therapy, a maintenance dose of $5 \mathrm{mg}$ prednisone daily was applied by 3 months post-transplant.

\section{Definition of PTDM}

PTDM was diagnosed according to the following criteria: 1) $\mathrm{HbA}_{1 \mathrm{c}} \geq 6.5 \%$; 2) $\mathrm{FPG} \geq 126 \mathrm{mg} / \mathrm{dL}(7.0 \mathrm{mmol} / \mathrm{L})$; 3) 2-hour plasma glucose $\geq 200 \mathrm{mg} / \mathrm{dL}(11.1 \mathrm{mmol} / \mathrm{L})$ during an oral glucose tolerance test; or 4) the patient had classic symptoms of hyperglycemia or hyperglycemic crisis, a random plasma glucose $\geq 200 \mathrm{mg} / \mathrm{dL}(11.1 \mathrm{mmol} / \mathrm{L}){ }^{15}$ The diagnosis of PTDM was performed between 1 month and 1 year post-transplant. We chose this time window (1 month to 1 year post-transplant) because 1) this period rules out recipients who develop transient hyperglycemia immediately after transplantation as a result of high-dose glucocorticoids and/or surgery stress; 2) the immunosuppressive regimen is relatively stable in this time window; and 3) a majority of PTDM occurs within the first year posttransplant. ${ }^{3,4}$ It is worth noting that time to the presence of PTDM post-transplant was also calculated and recorded for survival analyses.

\section{Pretransplant metabolic syndrome and its components}

Adapting the WHO 1999 and the International Diabetes Federation 2006 recommendations, ${ }^{16}$ as well as considering a Chinese standard, ${ }^{17}$ pretransplant metabolic syndrome was defined as the presence of any three or more of the following 
five components before transplantation: 1) FPG $>100 \mathrm{mg}$ / $\mathrm{dL}(5.6 \mathrm{mmol} / \mathrm{L}) ; 2)$ high-density lipoprotein cholesterol $(\mathrm{HDL}-\mathrm{C})<35 \mathrm{mg} / \mathrm{dL}(0.9 \mathrm{mmol} / \mathrm{L})$ in $\mathrm{men},<40 \mathrm{mg} / \mathrm{dL}$ $(1.0 \mathrm{mmol} / \mathrm{L})$ in women or drug treatment for low HDL-C; 3) $\mathrm{TG}>150 \mathrm{mg} / \mathrm{dL}(1.7 \mathrm{mmol} / \mathrm{L})$ or drug treatment for elevated TG; 4) $\mathrm{BMI}>28 \mathrm{~kg} / \mathrm{m}^{2}$; and 5) $\mathrm{SBP}>130 \mathrm{mmHg}$ or DBP $>85 \mathrm{mmHg}$ or drug treatment for hypertension. Data consisting of the five components were collected for analyses. Note that all the data represented the latest data that were obtained 2-3 days before transplantation. Pretransplant data reflecting the five components, including blood glucose, HDL-C level, TG level, BMI, SBP, DBP, and medications for low HDL-C or elevated TG or hypertension, were collected for analyses. These sets of data represented the latest pretransplant data that were routinely obtained 2-3 days before transplantation.

\section{Statistical analyses}

Data are expressed as mean $\pm \mathrm{SD}$, unless otherwise indicated. Statistical analyses were conducted with IBM SPSS Statistics v.19 (IBM Corporation, Armonk, NY, USA). Data sets of continuous variables were assessed for normal distribution and homogeneity of variance by the Kolmogorov-Smirnov and Levene's tests before analyses. The Student's $t$-test and chi-squared test were used to compare continuous and categorical variables, respectively, between patients with and without PTDM. To dissect potential pretransplant risk factors of PTDM, we first performed univariate analysis to assess the association of individual variables with the development of PTDM. Variables with a $P$-value $<0.1$ were selected for subsequent analyses using multivariable logistic regression and the Cox proportional hazards model to assess whether the relationship persisted. To determine whether metabolic syndrome and its components were relevant to the development of PTDM, we assigned the metabolic syndrome and its individual components with a binary value ( 0 for not present, 1 for present) and conducted further analyses using multivariable logistic regression and the Cox proportional hazards model. A $P$-value $<0.05$ was considered statistically significant.

\section{Results}

\section{Study cohort characteristics}

The included recipients were mainly on a tacrolimus-based regimen (tacrolimus $+\mathrm{MMF}+$ glucocorticoids) in the first year after transplantation. Of the included 633 non-diabetic kidney recipients, 26.2\% (166/633) developed PTDM in the first year post-transplant and the mean time to PTDM was 5.7 \pm 2.4 months. Among the PTDM patients, a majority (74.1\%) was diagnosed within 6 months after transplantation. The acute rejection post-transplant was similar between PTDM and non-PTDM patients ( $11.4 \%$ vs $10.7 \%, P=0.839)$. No differences were detected between PTDM and nonPTDM patients regarding gender composition, smoking, hematodialysis rate, hepatitis B virus (HBV) infection, $\mathrm{HCV}$ infection, antihypertensive medication, and statin use before transplantation; while the PTDM patients were older than non-PTDM patients $(P=0.012)$ and had a significantly increased family history of DM $(P=0.035)$. The percentage of pretransplant metabolic syndrome was apparently higher in PTDM compared with non-PTDM patients $(25.9 \%$ vs $14.6 \%, P=0.014)$. PTDM patients had obviously higher FPG $(5.6 \pm 0.9$ vs $4.8 \pm 1.1 \mathrm{mmol} / \mathrm{L}, P=0.026)$ and BMI $(26.4 \pm 4.6$ vs $\left.23.1 \pm 2.9 \mathrm{~kg} / \mathrm{m}^{2}, P=0.006\right)$, and a lower level of HDL-C $(1.14 \pm 0.19$ vs $1.24 \pm 0.23 \mathrm{mmol} / \mathrm{L}, P=0.015)$ compared with non-PTDM. The remaining components, plasma TG level and blood pressure, were similar between the two study groups. To exclude the potential disturbance of use of prednisone or tacrolimus (post-transplant factors) on the predictive power of the current study, we also took these factors into consideration. After careful comparison, we did not observe any differences regarding the dose or duration of prednisone or tacrolimus between PTDM and non-PTDM patients (data not included). The demographic characteristics and pretransplant laboratory parameters between PTDM and non-PTDM patients are shown in Table 1.

\section{Logistic regression analyses of pretransplant risk factors of PTDM}

To address the potential pretransplant risk factors of PTDM, we first conducted univariate logistic regression analyses (with unadjusted OR) for all the collected variables. The analyses showed that the following variables were associated with higher risk of PTDM $(P>0.1)$ : older age (OR 1.07, 95\% CI 1.02-1.12, $P=0.013$ ), family history of DM (OR 2.46, 95\% CI 1.05-5.74, $P=0.038$ ), and presence of metabolic syndrome (OR 3.50, 95\% CI 1.53-8.25, $P=0.011)$ as well as its components of $\mathrm{FPG}>5.6 \mathrm{mmol} / \mathrm{L}$ (OR 2.93, 95\% CI 1.28-6.71, $P=0.011$ ), $\mathrm{HDL}<0.9 \mathrm{mmol} / \mathrm{L}$ (men), $<1.0 \mathrm{mmol} / \mathrm{L}$ (women) (OR 2.74, 95\% CI 1.02-7.32, $P=0.045)$, TG $>1.7 \mathrm{mmol} / \mathrm{L}$ (OR 2.17, 95\% CI 0.92-5.12, $P=0.077)$, and $\mathrm{BMI}>28 \mathrm{~kg} / \mathrm{m}^{2}(\mathrm{OR} 3.92,95 \% \mathrm{CI}$ 0.99-15.53, $P=0.052$ ). Next, multivariable logistic regression analysis adjusted for age and family history of DM showed that presence of metabolic syndrome (adjusted 
Table I Characteristics and pretransplant metabolic syndrome in PTDM and non-PTDM patients

\begin{tabular}{|c|c|c|c|}
\hline Variables & $\begin{array}{l}\text { PTDM } \\
(n=166)\end{array}$ & $\begin{array}{l}\text { Non-PTDM } \\
(\mathrm{n}=467)\end{array}$ & $P$-value \\
\hline Age (years) & $54 \pm 9$ & $47 \pm 12$ & 0.012 \\
\hline Female gender (\%) & 45.8 & 46.9 & 0.901 \\
\hline Smoking (\%) & 25.9 & 23.6 & 0.790 \\
\hline Family history of DM (\%) & 37.3 & 19.5 & 0.035 \\
\hline Hematodialysis (\%) & 83.1 & 87.8 & 0.467 \\
\hline Time to PTDM (months) & $5.7 \pm 2.4$ & - & - \\
\hline HBV positive (\%) & 14.5 & 13.1 & 0.632 \\
\hline HCV positive (\%) & 8.4 & 7.7 & 0.783 \\
\hline $\begin{array}{l}\text { Antihypertensive } \\
\text { medication (\%) }\end{array}$ & 88.6 & 82.7 & 0.410 \\
\hline Statin medication (\%) & 22.9 & 20.3 & 0.565 \\
\hline Metabolic syndrome (\%) & 25.9 & 14.6 & 0.014 \\
\hline FPG $(\mathrm{mmol} / \mathrm{L})$ & $5.6 \pm 0.9$ & $4.8 \pm I . I$ & 0.026 \\
\hline HDL-C (mmol/L) & $1.14 \pm 0.19$ & $1.24 \pm 0.23$ & 0.015 \\
\hline TG $(\mathrm{mmol} / \mathrm{L})$ & $1.5 \mathrm{I} \pm 0.39$ & $1.40 \pm 0.44$ & 0.098 \\
\hline BMI $\left(\mathrm{kg} / \mathrm{m}^{2}\right)$ & $26.4 \pm 4.6$ & $23.1 \pm 2.9$ & 0.006 \\
\hline $\mathrm{SBP}(\mathrm{mmHg})$ & $139 \pm 15$ & $141 \pm 19$ & 0.362 \\
\hline $\mathrm{DBP}(\mathrm{mmHg})$ & $87 \pm 11$ & $85 \pm 13$ & 0.493 \\
\hline
\end{tabular}

Notes: Data are shown as mean \pm SD, otherwise indicated. To detect differences between PTDM and non-PTDM patients, the Student's $t$-test and chi-squared test were used to compare continuous and categorical variables, respectively.

Abbreviations: DM, diabetes mellitus; FPG, fasting plasma glucose; HBV, hepatitis $B$ virus; $\mathrm{HCV}$, hepatitis $\mathrm{C}$ virus; HDL-C, high-density lipoprotein cholesterol; PTDM, post-transplantation diabetes mellitus; TG, triglycerides.

OR $1.28,95 \%$ CI 1.04-1.51, $P=0.038$ ) was an independent predictor of development of PTDM. A separate multivariable logistic regression analysis incorporating the five metabolic syndrome components, as well as age and family history of DM, showed that both FPG $>5.6 \mathrm{mmol} / \mathrm{L}$ (adjusted OR 1.72,
95\% CI 1.14-2.29, $P=0.027$ ) and $\mathrm{BMI}>28 \mathrm{~kg} / \mathrm{m}^{2}$ (adjusted OR $1.59,95 \%$ CI $1.10-1.92, P=0.036)$ were also independent pretransplant risk factors (Table 2).

\section{Cox proportional hazards model for prediction of pretransplant risk factors of PTDM}

We next conducted survival analysis using a Cox proportional hazards model. By univariate analyses, we identified similar variables (as also identified through logistic regression analyses) associated with higher risk of PTDM: older age (OR 1.06, 95\% CI 1.02-1.09, $P=0.012$ ), family history of DM (OR 2.07, 95\% CI 1.04-4.10, $P=0.038$ ), and presence of metabolic syndrome (OR 3.35, 95\% CI 1.69-7.25, $P=0.006$ ) as well as its components of $\mathrm{FPG}>5.6 \mathrm{mmol} / \mathrm{L}$ (OR 2.60, 95\% CI 1.33-5.08, $P=0.005$ ), $\mathrm{HDL}<0.9 \mathrm{mmol} / \mathrm{L}$ (men), $<1.0 \mathrm{mmol} / \mathrm{L}$ (women) (OR 2.45, 95\% CI 1.15-5.25, $P=0.021$ ), TG $>1.7 \mathrm{mmol} / \mathrm{L}$ (OR $2.08,95 \%$ CI $1.03-4.18$, $P=0.040$ ), and BMI $>28 \mathrm{~kg} / \mathrm{m}^{2}$ (OR 2.63, 95\% CI 1.02-6.79, $P=0.045)$. By incorporating age, family history of DM and presence of metabolic syndrome into the model, we observed that presence of metabolic syndrome was able to predict PTDM independently (adjusted OR 2.75, 95\% CI 1.45-6.05, $P=0.021)$. By incorporating age, family history of DM, and the five metabolic syndrome components into the model, we found that BMI $>28 \mathrm{~kg} / \mathrm{m}^{2}$ (adjusted OR $3.19,95 \%$ CI $1.20-8.47, P=0.020$ ) was an independent risk factor of PTDM (Table 3).

\section{Discussion}

To our knowledge, this is the first attempt to address the impact of metabolic syndrome and its components on the

Table 2 Univariate and multivariable logistic regression analyses for prediction of risk factors of PTDM

\begin{tabular}{|c|c|c|c|c|}
\hline Variables & Unadjusted OR $(95 \% \mathrm{CI})$ & $P$-value & Adjusted OR $(95 \% \mathrm{Cl})$ & $P$-value \\
\hline Age by year & $1.07(1.02-1.12)$ & 0.013 & & \\
\hline Female gender & $1.02(0.47-2.20)$ & 0.967 & & \\
\hline Smoking & $1.17(0.54-2.55)$ & 0.691 & & \\
\hline Family history of DM & $2.46(1.05-5.74)$ & 0.038 & & \\
\hline Hemodialysis & $1.22(0.89-2.02)$ & 0.521 & & \\
\hline HBV positive & $1.37(0.60-3.14)$ & 0.453 & & \\
\hline HCV positive & $0.92(0.31-2.76)$ & 0.885 & & \\
\hline Antihypertensive medication & $1.63(0.5 \mathrm{I}-5.22)$ & 0.413 & & \\
\hline Statin medication & $1.11(0.42-2.94)$ & 0.545 & & \\
\hline Metabolic syndrome & $3.50(1.53-8.25)$ & 0.011 & $1.28(1.04-1.51)$ & 0.038 \\
\hline $\mathrm{FPG}>5.6 \mathrm{mmol} / \mathrm{L}$ & $2.93(I .28-6.7 I)$ & 0.011 & $1.72(1.14-2.29)$ & 0.027 \\
\hline $\mathrm{HDL}<0.9 \mathrm{mmol} / \mathrm{L}$ (men), $<1.0 \mathrm{mmol} / \mathrm{L}$ (women) & $2.74(1.02-7.32)$ & 0.045 & & \\
\hline $\mathrm{TG}>1.7 \mathrm{mmol} / \mathrm{L}$ & $2.17(0.92-5.12)$ & 0.077 & & \\
\hline $\mathrm{BMI}>28 \mathrm{~kg} / \mathrm{m}^{2}$ & $3.92(0.99-15.53)$ & 0.052 & $1.59(1.10-1.92)$ & 0.036 \\
\hline $\mathrm{SBP}>130 \mathrm{mmHg}$ or $\mathrm{DBP}>85 \mathrm{mmHg}$ & $2.17(0.64-7.34)$ & 0.265 & & \\
\hline
\end{tabular}

Abbreviations: DM, diabetes mellitus; FPG, fasting plasma glucose; HBV, hepatitis B virus; HCV, hepatitis C virus; HDL-C, high-density lipoprotein cholesterol; PTDM, post-transplantation diabetes mellitus; TG, triglycerides. 
Table 3 Cox proportional hazards model for prediction of pretransplant risk factors of PTDM

\begin{tabular}{|c|c|c|c|c|}
\hline Variables & Unadjusted OR $(95 \% \mathrm{Cl})$ & $P$-value & Adjusted OR (95\% Cl) & $P$-value \\
\hline Age by year & $1.06(1.02-1.09)$ & 0.012 & & \\
\hline Female gender & $1.02(0.53-1.98)$ & 0.949 & & \\
\hline Smoker & $1.12(0.58-2.18)$ & 0.736 & & \\
\hline Family history of DM & $2.07(1.04-4.10)$ & 0.038 & & \\
\hline Hemodialysis & $\mathrm{I} .37(0.6 \mathrm{I}-2.3 \mathrm{I})$ & 0.468 & & \\
\hline HBV positive & I.40 (0.70-2.82) & 0.344 & & \\
\hline HCV positive & $0.96(0.37-2.46)$ & 0.925 & & \\
\hline Antihypertensive medication & $1.50(0.53-4.25)$ & 0.445 & & \\
\hline Statin medication & $1.10(0.48-2.53)$ & 0.816 & & \\
\hline Metabolic syndrome & $3.35(1.69-7.25)$ & 0.006 & $2.75(1.45-6.05)$ & 0.021 \\
\hline $\mathrm{FPG}>5.6 \mathrm{mmol} / \mathrm{L}$ & $2.60(1.33-5.08)$ & 0.005 & & \\
\hline $\mathrm{HDL}<0.9 \mathrm{mmol} / \mathrm{L}$ (men), $<1.0 \mathrm{mmol} / \mathrm{L}$ (women) & $2.45(1.15-5.25)$ & 0.021 & & \\
\hline $\mathrm{TG}>1.7 \mathrm{mmol} / \mathrm{L}$ & $2.08(1.03-4.18)$ & 0.040 & & \\
\hline $\mathrm{BMI}>28 \mathrm{~kg} / \mathrm{m}^{2}$ & $2.63(1.02-6.79)$ & 0.045 & $3.19(1.20-8.47)$ & 0.020 \\
\hline $\mathrm{SBP}>130 \mathrm{mmHg}$ or $\mathrm{DBP}>85 \mathrm{mmHg}$ & $2.03(0.79-5.23)$ & 0.143 & & \\
\hline
\end{tabular}

Abbreviations: DM, diabetes mellitus; FPG, fasting plasma glucose; HBV, hepatitis B virus; HCV, hepatitis C virus; HDL-C, high-density lipoprotein cholesterol; PTDM, post-transplantation diabetes mellitus; TG, triglycerides.

development of PTDM in Chinese patients receiving a first kidney transplant. The major findings of the current study are: 1) pretransplant metabolic syndrome is an independent risk factor of the development of PTDM in Chinese patients, which is consistent with previous studies; 5,18 and 2) $\mathrm{FPG}>5.6 \mathrm{mmol} / \mathrm{L}$ and $\mathrm{BMI}>28 \mathrm{~kg} / \mathrm{m}^{2}$, two major metabolic syndrome components, are also independently associated with the development of PTDM. Because the components of the metabolic syndrome are manageable and/or can be treated with drugs, identification of these risk factors may allow timely intervention to prevent the development of PTDM.

In the general population, metabolic syndrome is frequently associated with the development of type $2 \mathrm{DM}$. Chakkera et al suggest that both PTDM and type $2 \mathrm{M}$ share highly overlapping pretransplant risk factors, of which the metabolic syndrome is a prominent one. ${ }^{1}$ The prevalence of metabolic syndrome in the present cohort was lower than that in previous studies, ${ }^{5,18}$ which may be due to ethnic differences. Nevertheless, we consistently found that pretransplant metabolic syndrome was an independent predictor for PTDM (Tables 2 and 3).

Metabolic syndrome is a cluster of five components, including obesity (BMI $>30 \mathrm{~kg} / \mathrm{m}^{2}$ ). In the Chinese population, BMI $>28 \mathrm{~kg} / \mathrm{m}^{2}$ is used as a clinical cutoff for obesity regardless of gender. ${ }^{17}$ It is a frequent finding that higher BMI, especially obesity, promotes the development of PTDM and increases the risk of graft loss..$^{3,7-9,19}$ In the current study with a Chinese cohort, by both multivariable logistic regression analysis and a Cox proportional hazards model, we consistently observed that pretransplant obesity was robustly associated with PTDM (Tables 2 and 3). Together with the finding that kidney recipients tend to gain weight posttransplant ${ }^{20}$ it therefore should be of clinical benefit to reduce BMI (eg, by modification of lifestyle) before transplantation, especially for obese recipients. It has been shown that higher muscle mass, rather than fat mass, predicts longer survival in dialysis patients. ${ }^{21,22}$ Therefore, interventions aimed at decreasing fat mass while increasing muscle mass pretransplant may decrease the incidence of PTDM. ${ }^{1}$

FPG $>5.6 \mathrm{mmol} / \mathrm{L}$, defined as impaired fasting glycemia (IFG), is a major component of metabolic syndrome. In the general population, IFG robustly predicts type $2 \mathrm{DM}^{23-25}$ In kidney recipients, however, it is still debated whether IFG is able to independently predict PTDM. Results from Chakkera et al and Cosio et al support a significant association between IFG and the development of PTDM, ${ }^{7,9}$ whereas Bayer et al provided negative results. ${ }^{5}$ When evaluated as a continuous variable, FPG is frequently associated with the development of PTDM. ${ }^{5,10}$ In the current study, we observed that IFG is a significant risk factor for PTDM, as assessed by the multivariable logistic regression analysis. Additional analysis incorporating plasma glucose as a continuous variable also gave similar results (data not shown). Therefore, we argue that pretransplant IFG is significantly associated with PTDM and that recipients with IFG may require glucoselowering therapy before kidney transplantation.

In the current study, using multivariable logistic regression analysis and a Cox proportional hazards model, we showed that older age and family history of DM were two independent predictors for PTDM (data not shown), which is consistent with previous findings. , $^{3,7,9,10,12}$ Gender and HBV infection were not significant risk factors for PTDM in our 
analyses, which is supported by previous studies. ${ }^{3,5,8,26} \mathrm{HCV}$ infection, a previously identified independent predictor, ${ }^{3,10,13}$ was not associated with PTDM in our observations. It has been documented that $\mathrm{HCV}$ promotes insulin resistance ${ }^{27}$ and that the diabetogenic effect is prompted by viral hindering of hepatic glucose and insulin metabolism. ${ }^{28-30}$ Although the HCV infection rates were similar between PTDM and non-PTDM patients in our study, it is still possible that the HCV disease was more active in the PTDM patients, which may partially contribute to the impaired glucose profile of this cohort. Therefore, to address more fully the relationship between HCV infection (as well as other infectious diseases, eg, HBV) and PTDM, the disease activity/severity should be taken into consideration.

There are three apparent limitations to this study. First, our data were retrospectively collected from a single center with a cohort of 633 recipients, which may be regarded as a relatively small, local sample size. Second, it is widely recognized that tacrolimus is more diabetogenic than other immunosuppressants, eg, cyclosporine. ${ }^{31-33}$ Although the immunosuppressive regimen was most often defined as tacrolimus based in our cohort, the dose and/or duration of tacrolimus were likely to vary between PTDM and non-PTDM patients, which could interfere with our analyses. Third, it is highly possible that some kidney recipients develop PTDM after 1 year post-transplant, which may introduce bias in our analysis. Therefore, future studies with larger sample size, longer follow-up, and stricter definitions of the immunosuppressive regimen are needed to confirm the current findings.

\section{Conclusion}

In summary, we have documented that pretransplant metabolic syndrome and its components, obesity (BMI $>28 \mathrm{~kg} / \mathrm{m}^{2}$ ) and IFG (FPG $>5.6 \mathrm{mmol} / \mathrm{L})$, are independent risk factors for the development of PTDM in Chinese non-diabetic patients receiving a first renal transplant. Interventions aimed at reversing obesity and/or IFG before transplantation may reduce the incidence of PTDM for kidney recipients in the Chinese population.

\section{Ethics approval}

The current study adhered to the Declaration of Helsinki and was approved by the Ethics Committee of The Third Affiliated Hospital of Guangzhou Medical University. All patients provided written informed consent.

\section{Data sharing statement}

Data will be available upon reasonable request, which also needs to be reviewed and approved by the ethics committee.

\section{Acknowledgments}

We would like to thank Drs Xuekun Guo and Minzhuan Lin (Department of Organ Transplantation, The Third Affiliated Hospital of Guangzhou Medical University) for assistance in data collection and analysis. The study was funded by the National Natural Science Foundation of China (no 81700645; to YX). The funder had no role in the study design, data collection and analysis, in the decision to publish, or in preparation of the manuscript.

\section{Disclosure}

The authors report no conflicts of interest in this work.

\section{References}

1. Chakkera HA, Weil EJ, Pham PT, Pomeroy J, Knowler WC. Can newonset diabetes after kidney transplant be prevented? Diabetes Care. 2013;36(5):1406-1412.

2. Sharif A, Baboolal K. Complications associated with new-onset diabetes after kidney transplantation. Nat Rev Nephrol. 2011;8(1):34-42.

3. Kasiske BL, Snyder JJ, Gilbertson D, Matas AJ. Diabetes mellitus after kidney transplantation in the United States. Am J Transplant. 2003; 3(2):178-185.

4. Woodward RS, Schnitzler MA, Baty J, et al. Incidence and cost of new onset diabetes mellitus among U.S. Wait-listed and transplanted renal allograft recipients. Am J Transplant. 2003;3(5):590-598.

5. Bayer ND, Cochetti PT, Anil Kumar MS, et al. Association of metabolic syndrome with development of new-onset diabetes after transplantation. Transplantation. 2010;90(8):861-866.

6. Matas AJ, Gillingham KJ, Humar A, et al. Posttransplant diabetes mellitus and acute rejection: impact on kidney transplant outcome. Transplantation. 2008;85(3):338-343.

7. Chakkera HA, Weil EJ, Swanson CM, et al. Pretransplant risk score for new-onset diabetes after kidney transplantation. Diabetes Care. 2011;34(10):2141-2145.

8. Bayés B, Granada ML, Pastor MC, et al. Obesity, adiponectin and inflammation as predictors of new-onset diabetes mellitus after kidney transplantation. Am J Transplant. 2007;7(2):416-422.

9. Cosio FG, Kudva Y, van der Velde M, et al. New onset hyperglycemia and diabetes are associated with increased cardiovascular risk after kidney transplantation. Kidney Int. 2005;67(6):2415-2421.

10. Lv C, Chen M, Xu M, et al. Influencing factors of new-onset diabetes after a renal transplant and their effects on complications and survival rate. PLoS One. 2014;9(6):e99406.

11. Montori VM, Basu A, Erwin PJ, Velosa JA, Gabriel SE, Kudva YC. Posttransplantation diabetes: a systematic review of the literature. Diabetes Care. 2002;25(3):583-592.

12. Sumrani NB, Delaney V, Ding ZK, et al. Diabetes mellitus after renal transplantation in the cyclosporine era - an analysis of risk factors. Transplantation. 1991;51(2):343-347.

13. Bloom RD, Rao V, Weng F, Grossman RA, Cohen D, Mange KC. Association of hepatitis $\mathrm{C}$ with posttransplant diabetes in renal transplant patients on tacrolimus. J Am Soc Nephrol. 2002;13(5):1374-1380.

14. Burroughs TE, Swindle J, Takemoto S, et al. Diabetic complications associated with new-onset diabetes mellitus in renal transplant recipients. Transplantation. 2007;83(8):1027-1034.

15. American Diabetes Association. Diagnosis and classification of diabetes mellitus. Diabetes Care. 2014;37(Suppl 1):S81-S90.

16. Alberti KG, Eckel RH, Grundy SM, et al. Harmonizing the metabolic syndrome: a joint interim statement of the International Diabetes Federation Task Force on Epidemiology and Prevention; National Heart, Lung, and Blood Institute; American Heart Association; World Heart Federation; International Atherosclerosis Society; and International Association for the Study of Obesity. Circulation. 2009;120(16):1640-1645. 
17. Wang Y, Mi J, Shan X-Y, Wang QJ, Ge K-Y. Is China facing an obesity epidemic and the consequences? The trends in obesity and chronic disease in China. Int J Obes (Lond). 2007;31(1):177-188.

18. Porrini E, Delgado P, Bigo C, et al. Impact of metabolic syndrome on graft function and survival after cadaveric renal transplantation. Am J Kidney Dis. 2006;48(1):134-142.

19. Meier-Kriesche HU, Arndorfer JA, Kaplan B. The impact of body mass index on renal transplant outcomes: a significant independent risk factor for graft failure and patient death. Transplantation. 2002; 73(1):70-74.

20. Cashion AK, Sánchez ZV, Cowan PA, Hathaway DK, Lo Costello A, Gaber AO. Changes in weight during the first year after kidney transplantation. Prog Transplant. 2007;17(1):40-47.

21. Beddhu S, Pappas LM, Ramkumar N, Samore M. Effects of body size and body composition on survival in hemodialysis patients. J Am Soc Nephrol. 2003;14(9):2366-2372.

22. Kalantar-Zadeh K, Streja E, Molnar MZ, et al. Mortality prediction by surrogates of body composition: an examination of the obesity paradox in hemodialysis patients using composite ranking score analysis. Am J Epidemiol. 2012;175(8):793-803.

23. Mancia G, Bombelli M, Facchetti R, et al. Long-term risk of diabetes, hypertension and left ventricular hypertrophy associated with the metabolic syndrome in a general population. J Hypertens. 2008;26(8): 1602-1611.

24. Ford ES, Li C, Sattar N. Metabolic syndrome and incident diabetes current state of the evidence. Diabetes Care. 2008;31(9):1898-1904.

25. Sattar N, McConnachie A, Shaper AG, et al. Can metabolic syndrome usefully predict cardiovascular disease and diabetes? Outcome data from two prospective studies. Lancet. 2008;371(9628):1927-1935.
26. Hamer RA, Chow CL, Ong AC, McKane WS. Polycystic kidney disease is a risk factor for new-onset diabetes after transplantation. Transplantation. 2007;83(1):36-40.

27. Delgado-Borrego A, Casson D, Schoenfeld D, et al. Hepatitis C virus is independently associated with increased insulin resistance after liver transplantation. Transplantation. 2004;77(5):703-710.

28. Aytug S, Reich D, Sapiro LE, Bernstein D, Begum N. Impaired IRS-1/ PI3-kinase signaling in patients with HCV: a mechanism for increased prevalence of type 2 diabetes. Hepatology. 2003;38(6):1384-1392.

29. Kawaguchi T, Yoshida T, Harada M, et al. Hepatitis C virus downregulates insulin receptor substrates 1 and 2 through up-regulation of suppressor of cytokine signaling 3. Am J Pathol. 2004;165(5):1499-1508.

30. Masini M, Campani D, Boggi U, et al. Hepatitis C virus infection and human pancreatic beta-cell dysfunction. Diabetes Care. 2005;28(4): 940-941.

31. Pirsch JD, Miller J, Deierhoi MH, Vincenti F, Filo RS. A comparison of tacrolimus (FK506) and cyclosporine for immunosuppression after cadaveric renal transplantation. FK506 Kidney Transplant Study Group. Transplantation. 1997;63(7):977-983.

32. Mayer AD, Dmitrewski J, Squifflet JP, et al. Multicenter randomized trial comparing tacrolimus (FK506) and cyclosporine in the prevention of renal allograft rejection: a report of the European Tacrolimus Multicenter Renal Study Group. Transplantation. 1997;64(3):436-443.

33. Knoll GA, Bell RC. Tacrolimus versus cyclosporin for immunosuppression in renal transplantation: meta-analysis of randomised trials. BMJ. 1999;318(7191):1104-1107.
Therapeutics and Clinical Risk Management

\section{Publish your work in this journal}

Therapeutics and Clinical Risk Management is an international, peerreviewed journal of clinical therapeutics and risk management, focusing on concise rapid reporting of clinical studies in all therapeutic areas, outcomes, safety, and programs for the effective, safe, and sustained use of medicines. This journal is indexed on PubMed Central, CAS,

\section{Dovepress}

EMBase, Scopus and the Elsevier Bibliographic databases. The manuscript management system is completely online and includes a very quick and fair peer-review system, which is all easy to use. Visit http://www.dovepress.com/testimonials.php to read real quotes from published authors.

Submit your manuscript here: http://www.dovepress.com/therapeutics-and-clinical-risk-management-journal 